\title{
Crystal Structure of $\left(\mathrm{NbSe}_{4}\right)_{3} \mathrm{I}$ and $\left(\mathrm{NbSe}_{4}\right)_{10 / 3} \mathrm{I}$ CDW Compounds at $14 \mathrm{~K}$
}

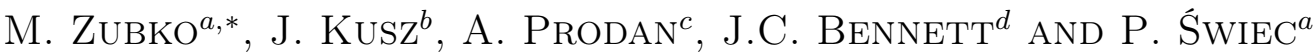 \\ ${ }^{a}$ Institute of Materials Science, University of Silesia, Chorzów, Poland \\ ${ }^{b}$ Institute of Physics, University of Silesia, Katowice, Poland \\ ${ }^{c}$ Jožef Stefan Institute, Ljubljana, Slovenia \\ ${ }^{d}$ Department of Physics, Acadia University, Wolfville, Canada
}

\begin{abstract}
Both $\left(\mathrm{NbSe}_{4}\right)_{3} \mathrm{I}$ and $\left(\mathrm{NbSe}_{4}\right)_{10 / 3} \mathrm{I}$ compounds are interesting system possessing quasi one-dimensional linear chain character and exhibiting nonlinear transport properties with a second order phase transition. The compounds are built of $\mathrm{NbSe}_{4}$ antiprisms, stacked along the tetragonal $c$ axis into chains in a screw-like arrangement. Performed $\mathrm{X}$-ray low temperature single crystal diffraction measurements allowed to solve, refine and analyze crystal structures of both compounds at $14 \mathrm{~K}$. While $\left(\mathrm{NbSe}_{4}\right)_{10 / 3} \mathrm{I}$ compound undergoes structural phase transition to monoclinic phase, $\left(\mathrm{NbSe}_{4}\right)_{3} \mathrm{I}$ remains in tetragonal symmetry. Iodine atoms are responsible for the differences in $\left(\mathrm{NbSe}_{4}\right)_{10 / 3} \mathrm{I}$ and $\left(\mathrm{NbSe}_{4}\right)_{3} \mathrm{I}$ structures causing different spacing in the infinite $\mathrm{NbSe}_{4}$ chains.
\end{abstract}

DOI: 10.12693/APhysPolA.130.869

PACS/topics: 61.50.Ks, 61.05.C-, 72.15.Nj, 61.72.Mm, 61.66.-f

\section{Introduction}

$\left(\mathrm{NbSe}_{4}\right)_{3} \mathrm{I}$ and $\left(\mathrm{NbSe}_{4}\right)_{10 / 3} \mathrm{I}$ compounds possess onedimensional character and belong to family of the $\left(\mathrm{MX}_{4}\right)_{n} \mathrm{Y}$ quasi one-dimensional (1D) linear chain compounds with $\mathrm{M}=\mathrm{Nb}$ or $\mathrm{Ta}, \mathrm{X}=\mathrm{S}$, Se or $\mathrm{Te}, \mathrm{Y}=\mathrm{Cl}, \mathrm{Br}$ or I, and $n=1,2,3$, or $10 / 3[1,2]$ with interesting physical properties. Both studied compounds are a semimetal at the room temperature and at lower temperatures transform into a semiconductor [3]. Both compounds exhibit nonlinear transport properties with a second order phase transition observed at $274 \mathrm{~K}$ for $\left(\mathrm{NbSe}_{4}\right)_{3} \mathrm{I}[4]$ and at $285 \mathrm{~K}$ for $\left(\mathrm{NbSe}_{4}\right)_{10 / 3} \mathrm{I}[5]$. The $\left(\mathrm{NbSe}_{4}\right)_{3} \mathrm{I}$ compound crystallizes in $P 4 / m n c$ space group, while $\left(\mathrm{NbSe}_{4}\right)_{10 / 3} \mathrm{I}$ crystallizes in $P 4 / m c c$. Nevertheless, the structures of both compounds at room temperature are closely related. The compounds are formed of $\mathrm{NbSe}_{4}$ antiprisms, aligned into chains along the tetragonal $c$ axis in a screw-like arrangement. The iodine atoms are positioned in two types of channels running along the $[00 z]$ and along the $\left[\frac{1}{2} \frac{1}{2} z\right]$ directions. The $\mathrm{Se}-\mathrm{Se}$ rectangles are rotated clockwise and anticlockwise along the $c$ axis. The differences between these structures are largely a result of a different iodine ordering. In $\left(\mathrm{NbSe}_{4}\right)_{3} \mathrm{I}$, the unit cell is composed of stack of $6 \mathrm{NbSe}_{4}$ antiprisms, while the unit cell of $\left(\mathrm{NbSe}_{4}\right)_{10 / 3} \mathrm{I}$ contains stack of $10 \mathrm{NbSe}_{4}$ units. In both studied compounds relative strong diffuse scattering is observed at $(h, k)$ planes in the form of concentric diffuse rings. Such observations were explained by a model based on a mismatch between the infinite $\mathrm{NbSe}_{4}$ chains with random shifts along the $c$ direction [6].

In order to compare crystal structures of studied compounds single crystal X-ray diffraction measurements were performed at liquid He temperatures.

\footnotetext{
*corresponding author; e-mail: maciej.zubko@us.edu.pl
}

\section{Experimental}

$\left(\mathrm{NbSe}_{4}\right)_{3} \mathrm{I}$ and $\left(\mathrm{NbSe}_{4}\right)_{10 / 3} \mathrm{I}$ have been studied using $\mathrm{X}$-ray and electron diffraction. Single crystals of both compounds were grown from the elements in evacuated quartz tubes at $923 \mathrm{~K}$. Good quality single crystals were selected under a stereoscopic microscope and then glued to quartz glass capillary. Temperature X-ray diffraction measurements were carried out using SuperNova four-circle X-ray diffractometer $\left(\mathrm{Cu} K_{\alpha} /\right.$ Mo $K_{\alpha}$ microsource) with Atlas CCD camera from Agilent Technologies. In the X-ray measurements crystals were cooled by a gas stream of cold dry nitrogen or helium using Oxford Cryosystem Cryostream 700 and HeliJet cooling attachments respectively, both providing temperature stability of $0.1 \mathrm{~K}$. Data reduction was carried out using CrysAllis $^{P R O}$ [7] software. The structures were solved by means of direct methods and refined with the SHELXS97 and SHELXL97 programs [8].

High resolution transmission electron microscopy (HRTEM) and selected area electron diffraction (SAED) studies were performed on high resolution JEOL JEM3010 electron microscope working at $300 \mathrm{kV}$ equipped with $2 \mathrm{k} \times 2 \mathrm{k}$ Orius $833 \mathrm{SC} 200 \mathrm{D}$ Gatan CCD camera. HRTEM and SAED experiments were performed on gently crushed crystals in agate martyr and then deposited on $\mathrm{Cu}$-grids covered with thin layer of amorphous carbon. Crushed crystals were dispersed in ultrasonic bath in methanol for $1 \mathrm{~h}$ in order to ensure good sample spread on the TEM grid.

\section{Results and discussion}

Due to the fact that crystallization conditions of the various compounds of the $\left(\mathrm{NbSe}_{4}\right)_{n} \mathrm{I}$ series are similar, multiple phases with essentially identical morphology were synthesized in the same batch. The actual compound could only be unambiguously distinguished on 
the basis of diffraction experiment. Two types of crystals were selected with unit cell parameters at roomtemperature (RT) equal to $a=b=9.4644(6) \AA$ and $c=31.9063(19) \AA, V=2859.3(3) \AA^{3}$ and $a=b=9.4904(2) \AA$ and $c=19.1264(8) \AA, V=$ $1722.67(8) \AA^{3}$, good corresponding with literature [1] to $\left(\mathrm{NbSe}_{4}\right)_{10 / 3} \mathrm{I}$ and $\left(\mathrm{NbSe}_{4}\right)_{3} \mathrm{I}$, respectively. Analysis of single crystal X-ray diffraction measurements, performed at room temperature (RT) confirmed that the structure of $\left(\mathrm{NbSe}_{4}\right)_{10 / 3} \mathrm{I}$ belongs to the $P 4 / m c c$ space group (no. 124), whereas the $\left(\mathrm{NbSe}_{4}\right)_{3} \mathrm{I}$ compound belongs to the space group $P 4 / m n c$ (no. 128). Furthermore, X-ray diffraction showed strong diffuse scattering in form of strong diffuse streaking perpendicular to the $c *$ direction for both compounds.

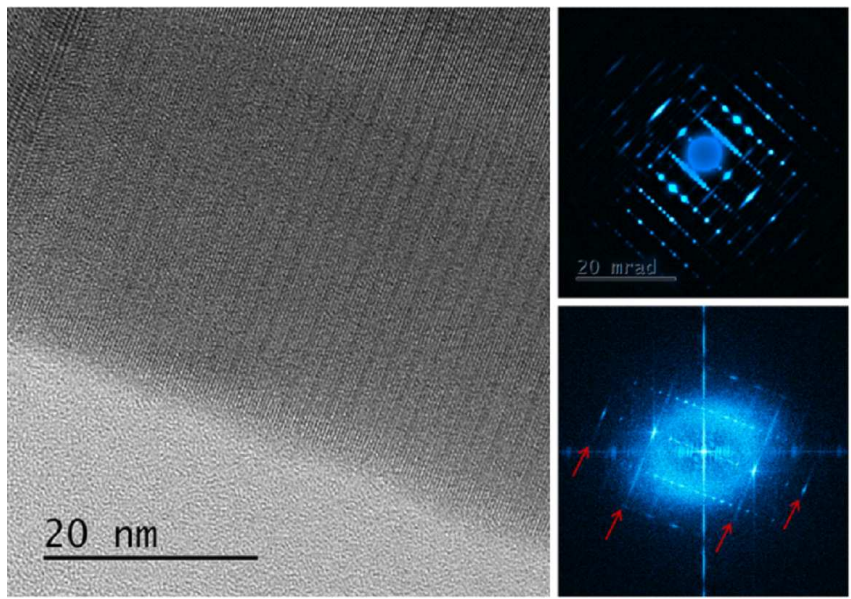

Fig. 1. The experimental HRTEM image of $\left(\mathrm{NbSe}_{4}\right)_{3} \mathrm{I}$, viewed along the [110] direction with the corresponding SAED and FFT patterns. The diffuse streaking perpendicular to the $c *$ direction is marked by arrows.

Performed transmission electron microscopy study also revealed structural mismatch (Fig. 1). Similar diffuse scattering features (strong diffuse streaking at $l=6$ ) are visible on the selected area electron diffraction patterns. The Fourier transform calculated from the recorded high resolution transmission electron micrograph also shows corresponding diffuse scattering streaks. In the case of $\left(\mathrm{NbSe}_{4}\right)_{10 / 3} \mathrm{I}$ it has been shown [6] that the diffuse scattering at $l=10 n$ is associated with one-dimensional (1D) displacements of the $\mathrm{NbSe}_{4}$ chains along the $c$ axis.

Performed low temperature X-ray single crystal diffraction measurements at $14 \mathrm{~K}$ showed that $\left(\mathrm{NbSe}_{4}\right)_{3} \mathrm{I}$ compound still possesses tetragonal symmetry, but the symmetry is reduced from $P 4 / m n c$ (no. 128 ) above $274 \mathrm{~K}$ through $P \overline{4} 2_{1} c$ (no. 114) at intermediate phase to the final $P \overline{4}$ space group (no. 81 ) at low temperature phase. The crystal structure is with good accordance with the one already published for this compound measured at $30 \mathrm{~K}$ [9]. Lattice parameter at $14 \mathrm{~K}$ were determined as follows to $a=b=9.4203(1) \AA$ and $c=19.0655(3) \AA$, $V=1691.91(4) \AA^{3}$.
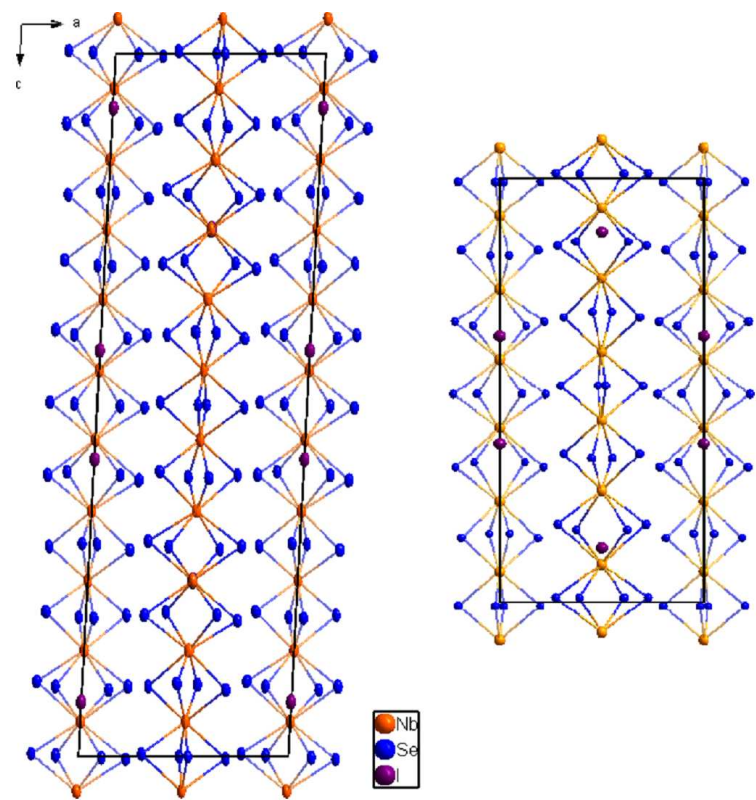

Fig. 2. Projection of the $\left(\mathrm{NbSe}_{4}\right)_{10 / 3} \mathrm{I}$ structure (left) and $\left(\mathrm{NbSe}_{4}\right)_{3} \mathrm{I}$ structure (right) along $b$ direction both solved at $14 \mathrm{~K}$.

On the other hand, during cooling $\left(\mathrm{NbSe}_{4}\right)_{10 / 3} \mathrm{I}$ compound undergoes structural phase transition to monoclinic symmetry, which is accompanied with fourfold twinning. Performed low temperature X-ray single crystal diffraction measurements at $14 \mathrm{~K}$ showed that the space group $P 2 / c$ (no. 13) remains unchanged. The lattice parameters of the low temperature phase at $14 \mathrm{~K}$ were determined as follows to $a=9.4375(2) \AA, b=$ 9.4250(2) $\AA, c=31.8440(6) \AA$, and $\beta=93.041(2)^{\circ}$, $V=1691.91(4) \AA^{3}$. For both compounds diffuse scattering was not observed at $14 \mathrm{~K}$. The detailed information regarding structure refinements are gathered in Table I.

The structure of $\left(\mathrm{NbSe}_{4}\right)_{10 / 3} \mathrm{I}$ is built of the $\mathrm{Nb}$ atoms assembled into $\mathrm{Nb}_{2}$ and $\mathrm{Nb}_{3}$ sections with variable $\mathrm{Nb}-$ $\mathrm{Nb}$ distances. Selenium atoms create cages correlating with the Nb groups (Fig. 2 and Fig. 3). The structures of the high temperature - tetragonal phase and low temperature - monoclinic phase are similar (Fig. 3), except for the slight deformations of the coordination polyhedra in the monoclinic phase. During cooling the deformation of the $\mathrm{Se}_{4}$ rectangles takes place - they are slightly tilted and not any more perpendicular to the $c$-axis. The $\mathrm{Nb}-$ $\mathrm{Nb}$ distances do not change drastically and the structure conserves $\mathrm{Nb}_{2}$ and $\mathrm{Nb}_{3}$ assembles. Also the iodine atoms remain on the same positions in the unit cell occupying channels along $c$ direction between $\mathrm{NbSe}_{4}$ chains. Due to symmetry reduction in low temperature phase two adjacent $\mathrm{NbSe}_{4}$ chains became symmetrically independent. Nevertheless, both chains do not differ strongly - the $\mathrm{Nb}-\mathrm{Nb}$ distances and $\mathrm{Nb}$ arrangement remains nearly unchanged. The main differences is visible on the SeSe rectangles that became more deformed. 
TABLE I

Structure refinement details for $\left(\mathrm{NbSe}_{4}\right)_{3} \mathrm{I}$ and $\left(\mathrm{NbSe}_{4}\right)_{10 / 3} \mathrm{I}$ at $14 \mathrm{~K}$.

\begin{tabular}{l|c|c}
\hline \hline Compound name & $\left(\mathrm{NbSe}_{4}\right)_{3} \mathrm{I}$ & $\left(\mathrm{NbSe}_{4}\right)_{10 / 3} \mathrm{I}$ \\
\hline chemical formula & $\mathrm{I}_{2} \mathrm{Nb}_{6} \mathrm{Se}_{24}$ & $\mathrm{I}_{3} \mathrm{Nb}_{10} \mathrm{Se}_{40}$ \\
formula mass & 2706.30 & 4468.20 \\
crystal system & tetragonal & monoclinic \\
$a[\AA]$ & $9.4203(1)$ & $9.4375(2)$ \\
$b[\AA]$ & $9.4203(1)$ & $9.4250(2)$ \\
$c[\AA]$ & $19.0655(3)$ & $31.8440(6)$ \\
$\alpha\left[^{\circ}\right]$ & 90 & 90 \\
$\beta\left[^{\circ}\right]$ & 90 & $93.041(2)$ \\
$\gamma\left[^{\circ}\right]$ & 90 & 90 \\
unit cell volume $[\AA]^{3}$ & $1691.91(4)$ & $2828.49(10)$ \\
Temperature $[\mathrm{K}]$ & 14 & 14 \\
space group & $P \overline{4}$ & $P 2 / c$ \\
formula units per unit cell, $Z$ & 2 & 2 \\
radiation type & $\mathrm{Mo}_{K \alpha}$ & $\mathrm{Cu} K \alpha$ \\
absorption coefficient, $\mu\left[\mathrm{mm}{ }^{-1}\right]$ & 29.609 & 58.342 \\
no. of reflections measured & 15679 & 4357 \\
no. of independent reflections & 9214 & 4357 \\
final $r_{1}$ values $(i>2 \sigma(i))$ & 0.0528 & 0.1182 \\
final $w R\left(F^{2}\right)$ values $(i>2 \sigma(i))$ & 0.1210 & 0.5083 \\
final $r_{1}$ values $($ all data) & 0.0729 & 0.1184 \\
final $w R\left(F^{2}\right)$ values $($ all data) & 0.1324 & 0.5200 \\
goodness of fit on $F^{2}$ & 1.078 & 3.059 \\
& &
\end{tabular}
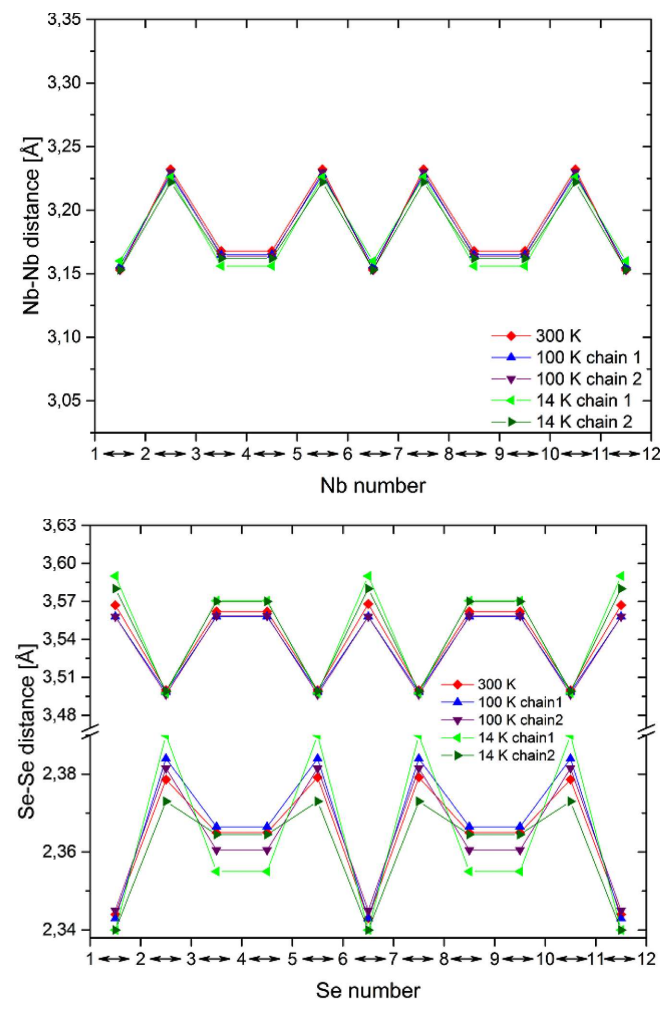

Fig. 3. $\left(\mathrm{NbSe}_{4}\right)_{10 / 3} \mathrm{I}-$ comparison of $\mathrm{Nb}-\mathrm{Nb}$ (left) and $\mathrm{Se}-\mathrm{Se}$ (right) distances at 300, 100, and $14 \mathrm{~K}$ indicating formation of the $\mathrm{Nb}_{2}-\mathrm{Nb}_{3}$ chains.
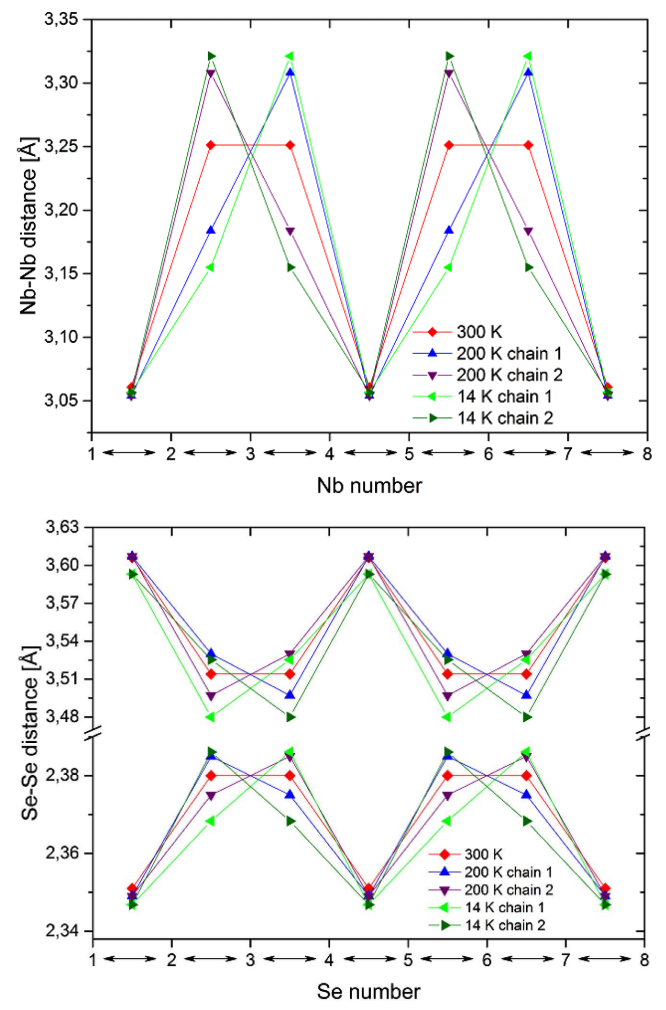

Fig. 4. $\left(\mathrm{NbSe}_{4}\right)_{3} \mathrm{I}$ - comparison of $\mathrm{Nb}-\mathrm{Nb}$ (left) and Se-Se (right) distances at 300,200 , and $14 \mathrm{~K}$ indicating formation of the $\mathrm{Nb}_{2}-\mathrm{Nb}-\mathrm{Nb}-\mathrm{Nb}_{2}$ chains.

The structure of $\left(\mathrm{NbSe}_{4}\right)_{3} \mathrm{I}$ compound is built of the $\mathrm{Nb}$ atoms assembled into $\mathrm{Nb}_{2}-\mathrm{Nb}-\mathrm{Nb}-\mathrm{Nb}_{2}$ chains (Fig. 4). As in the related $\left(\mathrm{NbSe}_{4}\right)_{10 / 3} \mathrm{I}$ structure, selenium atom create rectangles bonding two adjacent niobium atoms. The intermediate and low temperatures structures differs from the high temperature one quite strongly. The high temperature space group is centrosymmetric, while the intermediate and low temperature one are noncentrosymmetric. First of all, the $\mathrm{Nb}_{2}-\mathrm{Nb}-\mathrm{Nb}-\mathrm{Nb}_{2}$ sequence is violated. One of the two separated niobium atom approaches the $\mathrm{Nb}_{2}$ group and increases distance to the other single $\mathrm{Nb}$ atom. Assembly of niobium atoms changes into group of three $\mathrm{Nb}$ atoms with increased distance between neighbouring $\mathrm{Nb}_{3}$ groups. The selenium atom also correlates with the $\mathrm{Nb}$ atoms increasing deformation of the Se rectangles. Two adjacent $\mathrm{NbSe}_{4}$ chains are related by the $\overline{4}$ symmetry operator. Due to that sequence of $\mathrm{Nb}$ distances along $c$ axis in two adjacent chains is reversed. The iodine atoms remain on the same positions in all phases occupying channels along $c$ direction between $\mathrm{NbSe}_{4}$ chains.

\section{Conclusions}

Structural analysis of the low temperature (at $14 \mathrm{~K}$ ) phases of $\left(\mathrm{NbSe}_{4}\right)_{10 / 3} \mathrm{I}$ and $\left(\mathrm{NbSe}_{4}\right)_{3} \mathrm{I}$ compounds was performed. Both structures were refined for the first time at such low temperature. Measurements confirmed 
that $\left(\mathrm{NbSe}_{4}\right)_{3} \mathrm{I}$ compound possesses $P \overline{4}$ space group. The structural analysis performed for the $\left(\mathrm{NbSe}_{4}\right)_{10 / 3} \mathrm{I}$ at helium temperatures showed that studied compound remains in $P 2 / c$ space group. For both compound diffuse scattering was not observed at $14 \mathrm{~K}$.

The crystal structure of $\left(\mathrm{NbSe}_{4}\right)_{10 / 3} \mathrm{I}$ changes only slightly with the phase transition, whereas $\left(\mathrm{NbSe}_{4}\right)_{3} \mathrm{I}$ structure exhibits more significant differences. Especially the $\mathrm{Nb}$ atom group and the adjacent $\mathrm{NbSe}_{4}$ chains are reversed in different manner.

Iodine atoms are responsible for the differences in $\left(\mathrm{NbSe}_{4}\right)_{10 / 3} \mathrm{I}$ and $\left(\mathrm{NbSe}_{4}\right)_{3} \mathrm{I}$ structures. The main features of both structures are familiar but the most significant differences are the amount of I atoms causing different spacing in the infinite $\mathrm{NbSe}_{4}$ chains. At room temperature in both structures iodine atoms exhibit disorder along $c$ direction, whereas at $14 \mathrm{~K}$ iodine atoms are localized.

\section{References}

[1] A. Meerschaut, J. Rouxel, in: Crystal Chemistry and Properties of Materials with Quasi-One-Dimensional Structures: A Chemical and Physical Synthetic Approach, Ed. J. Rouxel, Springer, Netherlands 1986, p. 205.
[2] W. Tremel, Chem. Ber. 125, 2165 (1992).

[3] M. Izumi, T. Iwazumi, T. Seino, K. Uchinokura R. Yoshizeki, E. Matsuura, Solid State Commun. 49 , 423 (1984).

[4] P. Gressier, L. Guemas, A. Meerschaut, Mater. Res. Bull. 20, 539 (1985).

[5] C. Roucau, R. Ayrolesw, P. Gressier, A. Meerschaut, J. Phys. C 17, 2993 (1984).

[6] M. Zubko, J. Kusz, A. Prodan, S. Sturm, H.J.P. van Midden, J.C. Bennett, G. Dubin, E. Zupanic, H. Böhm, Acta Crystallogr. B 69, 229 (2013).

[7] Agilent CrysAlis ${ }^{\mathrm{PRO}}$, Agilent Technologies Ltd., Yarnton, Oxfordshire 2016.

[8] G.M. Sheldrick, SHELX97, Programs for Crystal Structure Analysis, Release 97-2, University of Göttingen, Germany 1997.

[9] M. Izumi, T. Iwazumi, T. Seino, T. Sekine, E. Matsuura, K. Uchinokura, R. Yoshizaki, Synth. Met. 19 , 863 (1987). 